\title{
The Relationship between Personality Organization and Psychiatric Classification in Chronic Pain Patients
}

\author{
Melitta Fischer-Kern ${ }^{a} \quad$ Nestor D. Kapusta ${ }^{a} \quad$ Stephan Doering ${ }^{c, d} \quad$ Susanne Hörz ${ }^{e}$ \\ Christian Mikutta $^{\mathrm{a}, \mathrm{b}}$ Martin Aigner ${ }^{\mathrm{b}}$ \\ Departments of a Psychoanalysis and Psychotherapy, and b Psychiatry and Psychotherapy, Medical University of \\ Vienna, Vienna, Austria; ${ }^{C}$ Psychosomatics in Dentistry, Department of Prosthodontics and Material Sciences, and \\ ${ }^{\mathrm{d} D e p a r t m e n t}$ of Psychosomatics and Psychotherapy, University of Muenster, Muenster, and ${ }^{\mathrm{e}}$ Department of \\ Psychology, University of Munich, Munich, Germany
}

\section{Key Words}

Chronic pain - Psychiatric comorbidity • Psychic structure •

Structured Interview of Personality Organization

\begin{abstract}
Background: The present study investigated the relationship between psychiatric classification and personality organization (PO) in a secondary/tertiary clinical sample of chronic pain patients (CPPs). Sampling and Methods: Forty-three patients were administered the Structured Clinical Interview for DSM-IV (SCID I+II) and the Structured Interview of Personality Organization (STIPO). The prevalence of axis I and axis II disorders was correlated with the STIPO level of PO. The STIPO dimensional ratings of patients without personality disorder (PD) were compared to those of patients diagnosed with one or more PDs. Results: Axis I comorbidity was high (93\%), and $63 \%$ of the patients met the criteria for at least one axis II diagnosis. Twenty-five patients (58\%) were diagnosed as borderline PO, with high-level impairments in the dimensions 'coping/rigidity', 'primitive defenses' and 'identity'. Higher axis I and axis II comorbidity corresponded with greater severity of PO impairment. No difference was found between the dimensional ratings of patients without PD and those of patients with one or more PDs. Conclusions:
\end{abstract}

The assessment of $\mathrm{PO}$ is a crucial issue for diagnosis and treatment planning in CPPs, since it represents a measure of structural impairment that is to a considerable extent independent of axis I and II diagnoses. Moreover, the STIPO dimensional rating focuses on the most salient dysfunctions at a given time.

Copyright $\odot 2010$ S. Karger AG, Basel

\section{Introduction}

According to the International Association for the Study of Pain, pain is 'an unpleasant sensory and emotional experience associated with actual or potential tissue damage, or described in terms of such damage'. This broad definition recognizes that sensory fibers reflecting tissue damage and emotional factors reflecting suffering form an amalgam that is difficult to sort out. Chronic pain, defined as pain which has been present for more than 6 months [1], is often associated with psychopathology. Among the most common psychiatric disorder diagnoses that chronic pain patients (CPPs) receive is pain disorder, which is one of the somatoform disorders listed in DSM-IV. However, the DSM definitions of the criteria for somatoform disorders have been widely criticized

\section{KARGER}

Fax +41613061234 E-Mail karger@karger.ch www.karger.com
(C) 2010 S. Karger AG, Basel

0254-4962/11/0441-0021\$38.00/0

Accessible online at:

www.karger.com/psp
Melitta Fischer-Kern, MD

Department of Psychoanalysis and Psychotherapy, Medical University of Vienna

Währinger Gürtel 18-20, AT-1090 Vienna (Austria)

Tel. +431 404003 067, Fax +431406 6803

E-Mail melitta.fischer-kern@medunwien.ac.at 
over the years [2,3], and a new diagnostic system has been proposed for DSM-V [4]. Studies revealed high variability of comorbid depressive disorders and anxiety disorders [5], and syndrome overlap of depression, anxiety and somatization was reported [6, 7]. High rates of personality disorders (PDs) have been documented in CPPs, with a prevalence ranging from 31 [8] to $81 \%$ [9]. Little consistency has been found in terms of specific PDs, with histrionic [10], dependent [11], paranoid [12] and borderline PDs [8] identified as the most common specific axis II disorders. Moreover, diagnoses of PDs in CPPs based on the Structured Clinical Interview for DSM-IV (SCID) have failed to show the expected degree of diagnostic stability over time [5].

Alternative approaches to the assessment of personality in the chronic pain population have identified different personality traits associated with chronic pain. The Minnesota Multiphasic Personality Inventory suggested somatization and denial as modal defense strategies in CPPs [13]. The NEO Personality Inventory identified a relationship between neuroticism and introversion and the development and maintenance of chronic pain [14]. The Temperament and Character Inventory revealed higher scores on the 'harm avoidance' temperament and lower scores on the dimensions 'self-directedness' and 'cooperativeness' [15]. However, assessments of personality traits primarily based on self-report inventories have also been brought into question [16].

Looking for new ways of assessing personality, psychoanalytic research has identified a number of key structural elements contributing to an individual's personality functioning [17-19]. A well-established approach to the assessment of psychic structure is Kernberg's model of personality organization (PO) [18]. The model differentiates 3 levels of $\mathrm{PO}$ according to the domains identity integration, defense mechanisms and reality testing. Neurotic PO is characterized by mature defense mechanisms, good sense of identity and reality testing. Borderline PO is characterized by immature defense mechanisms and identity diffusion, whereas reality testing is generally maintained. Psychotic PO is marked by archaic defense mechanisms, severe identity diffusion and poor reality testing. The Structured Interview of Personality Organization (STIPO) [20] provides a guide to the evaluation of the individual's PO according to Kernberg's psychodynamic conceptualization. The STIPO allows a dimensional rating of several domains central to personality functioning and a more refined assessment of the level of PO.
To date, the German version of the STIPO has been employed in several clinical studies. In borderline PD (BPD) patients, one study revealed a correlation between low levels of PO and clinical severity [21] and a second study showed correlations between the level of PO and the number of axis I and axis II diagnoses [22]. PO has also been used as a measure of change in psychotherapy. In a randomized, controlled trial, transference-focused psychotherapy was shown to be significantly superior in terms of changing levels of PO in comparison to treatment of BPD patients by experienced community psychotherapists [23]. Walter et al. [24] investigated negative affects and identity disturbance according to the STIPO in patients with BPD and patients without PD.

The principal aim of the study was to apply the concept of PO to the investigation of CPPs and to relate this structural diagnostic approach to the categorical classification of the DSM-IV. We firstly investigated psychiatric comorbidity according to axis I and II diagnoses and psychic structure according to the STIPO level of PO and STIPO dimensional ratings. Then we assessed the relationship between the two constructs in terms of the correlation between the number of axis I and axis II diagnoses and the level of PO. Finally, we explored the STIPO dimensional ratings of patients without $\mathrm{PD}$ and those of patients diagnosed with one or more PDs.

We hypothesized a high prevalence of axis I and II disorders in our secondary/tertiary clinical sample. In addition, we hypothesized a higher prevalence of low-level PO in comparison to the general population. We expected that higher numbers of axis I and II diagnoses would be associated with lower levels of PO. Finally, we also expected significant differences between the STIPO dimensional ratings of patients without $\mathrm{PD}$ and patients with PD.

\section{Methods}

Study Sample and Procedure

During the study period, from July 2006 to May 2008, all patients referred to the Behavioral Medicine Pain Clinic in the Department of Psychiatry and Psychotherapy of the University of Vienna as candidates for behavioral group therapy were consecutively assigned to the study. Patients aged between 18 and 65 years with chronic pain conditions according to International Association for the Study of Pain [1] criteria were included. Patients were excluded if they met criteria for schizophrenia, bipolar disorder, severe substance abuse or mental retardation. A total of $50 \mathrm{pa}-$ tients were eligible for the study, and complete data were available for 43 patients. All patients provided written informed consent. The study was approved by the ethical board of the Medical University of Vienna. 
The sample consisted of 38 women and 5 men with an average age of 51.5 years $(S D \pm 8.9$, minimum $=27$, maximum $=65)$. With regard to civil status, $63 \%$ of the participants were married, $19 \%$ divorced, $5 \%$ widowed and $12 \%$ single. The highest educational attainment for $30 \%$ was compulsory school, for $37 \%$ vocational school, for $21 \%$ secondary school and for $7 \%$ tertiary studies. With regard to employment status, $21 \%$ of the patients were employed, $26 \%$ unemployed, $44 \%$ retired (partly due to their disorder) and $7 \%$ were housewives.

The participants represented a heterogeneous group of CPPs, including those with low back and leg pain, head, neck and arm pain, orofacial pain, and skin and muscular pain. Three quarters of the patients (76\%) suffered from permanent pain and $67 \%$ reported multilocular pain. Three quarters of the patients (74\%) had suffered from pain for more than 2 years, $16 \%$ for more than 1 year and $7 \%$ for more than 6 months. Pain intensity during the previous month was $6.9(\mathrm{SD} \pm 2.0$, minimum $=3$, maximum $=10$ ), disability in work was 7.9 and disability in leisure was 7.8 on the 10 -point visual analogue scale.

\section{Measures}

Structured Clinical Interview for DSM-IV

Psychiatric disorders according to DSM-IV were assessed by the German versions of the SCID-I [25] and SCID-II [26].

\section{Structured Interview of Personality Organization}

The STIPO [20] is a 100-item semistructured interview that yields 7 dimensions of personality functioning: (1) identity consolidation; (2) quality of object relations; (3) use of primitive defenses; (4) quality of aggression; (5) adaptive coping versus character rigidity; (6) moral values, and (7) reality testing and perceptual distortions. In addition to the item-based scoring method, which was examined by Stern et al. [27], the interviewer can complete a clinical rating for each dimension ranging from absence of pathology (score of 1 ) to very severe pathology (score of 5) on a 5-point scale. These 5-point clinical ratings yield a personality profile that depicts the individual's functioning on the different dimensions. Moreover, the level of PO is scored on a 6-point scale according to which subjects can be described as falling within the normal, neurotic (neurotic 1 , neurotic 2 ) or borderline (borderline 1 to borderline 3 ) level of PO. Thus, borderline 1 , borderline 2 and borderline 3 represent increasing PO pathology across the dimensions of the STIPO. A detailed description of the instrument is given by Hörz [28]. The psychometric qualities of the STIPO have been shown to be adequate to good, with high interrater reliability data for all of the STIPO domains, ranging from 0.84 to 0.97 , a mean intraclass correlation coefficient of 0.92 and generally high internal consistency for the 7 STIPO domains, with Cronbach's alpha ranging from 0.63 (reality testing) to 0.92 (object relations), with a mean of 0.83 [27].

SCID interviews were conducted by two psychiatrists who received comprehensive interview training and demonstrated satisfactory reliability. STIPO interviewers (C.M., S.H.) were trained by the respective authors of the English (at the Personality Disorders Institute, White Plains, N.Y., USA) and German version (at the University of Innsbruck, Innsbruck, Austria) of the instrument and had obtained good interrater reliability. The intraclass correlation coefficient of the STIPO clinical ratings was 0.70 . STIPO interviewers were blinded to SCID results.

Personality Organization and Psychiatric

Classification in Chronic Pain Patients
Table 1. Axis I and axis II disorders in our sample of CPPs

Patients, $\mathrm{n}$
Substance abuse

Affective disorders

Anxiety disorders

Somatoform disorders

Adjustment disorders

Number of axis I diagnoses

0

1 or more

2 or more

3 or more

Axis II diagnoses

Avoidant

Dependent

Obsessive-compulsive

Depressive

Paranoid

Schizotypal

Schizoid

Histrionic

Narcissistic

Borderline

Antisocial

Number of axis II diagnoses

0

1 or more

2 or more

3 or more
Axis I diagnoses
$6(14.0 \%)$

$29(67.4 \%)$

$15(34.9 \%)$

$36(83.7 \%)$

$2(4.7 \%)$

$3(7.0 \%)$

$40(93.0 \%)$

$34(79.0 \%)$

$14(32.6 \%)$

$3(7.0 \%)$

$5(11.6 \%)$

$12(27.9 \%)$

$6(14.0 \%)$

$7(16.3 \%)$

$1(2.3 \%)$

$4(9.3 \%)$

$3(7.0 \%)$

$11(25.6 \%)$

$16(37.2 \%)$

$27(62.8 \%)$

$16(37.2 \%)$

$7(16.3 \%)$
Statistical Analysis

The relationship between the number of axis I and axis II diagnoses and the level of PO was tested by Spearman correlations. To compare scores for the STIPO dimensional ratings of patients with no PD and patients with PD, Mann-Whitney tests were applied. The significance level was set at $\mathrm{p}<0.05$ using SPSS 14.0.

\section{Results}

Table 1 presents the prevalence rates of axis I and axis II disorders. Somatoform disorders (83.7\%) and mood disorders (67.4\%) were the most frequent axis I disorders, and $93 \%$ of the patients were diagnosed with one or more axis I disorders. Of the somatoform disorders, $14.3 \%$ were somatization disorder, $17.8 \%$ were undifferentiated somatoform disorder, $57.1 \%$ were pain disorder and $10.7 \%$ were somatoform disorder not otherwise specified. On axis II, obsessive-compulsive (27.9\%) and borderline (25.6\%) PDs were predominant, and $62.8 \%$ of the patients were diagnosed with one or more axis II disorders. 
Table 2. STIPO level of PO and dimensional ratings

\begin{tabular}{|c|c|}
\hline Level of PO & CPPs, $\mathrm{n}$ \\
\hline Normal & $1(2.3 \%)$ \\
\hline Neurotic 1 & $6(14.0 \%)$ \\
\hline Neurotic 2 & $11(25.6 \%)$ \\
\hline Borderline 1 & $20(46.5 \%)$ \\
\hline Borderline 2 & $3(7.0 \%)$ \\
\hline Borderline 3 & $2(4.7 \%)$ \\
\hline Dimensional rating & Mean $\pm \mathrm{SD}$ \\
\hline 1 Identity & $2.79 \pm 0.68$ \\
\hline 2 Quality of object relationships & $2.40 \pm 0.88$ \\
\hline 3 Primitive defenses & $2.81 \pm 0.70$ \\
\hline 4 Coping/rigidity & $3.00 \pm 0.79$ \\
\hline 5 Aggression & $2.26 \pm 0.73$ \\
\hline 6 Moral values & $1.40 \pm 0.66$ \\
\hline $7 \quad$ Reality testing and perceptual distortions & $1.95 \pm 0.84$ \\
\hline
\end{tabular}

Table 2 presents the assignment of the PO level and the ratings of each dimension of the STIPO. The prevalence of borderline PO was 58.2\%, and the most severe level of impairment was found in the dimension 'coping/rigidity'.

The level of $\mathrm{PO}$ was associated with the number of axis $\mathrm{I}(\mathrm{r}=0.364, \mathrm{p}=0.016)$ and axis II diagnoses $(\mathrm{r}=330, \mathrm{p}=$ $0.031)$. Out of the 16 patients without PD, 10 patients (62.5\%) were diagnosed as having neurotic $\mathrm{PO}$ and $6 \mathrm{pa}-$ tients (37.5\%) were diagnosed as having borderline PO. Out of the 27 patients with one or more PDs, 8 (29.6\%) were diagnosed as having neurotic PO and 19 (70.4\%) were diagnosed as having borderline PO. According to the STIPO dimensional ratings, no significant difference was found between patients with $\mathrm{PD}$ and patients without PD on Mann-Whitney tests (fig. 1).

\section{Discussion}

The present study investigated the psychiatric comorbidity and PO in a secondary/tertiary clinical sample of CPPs. In line with previous studies [5], we found high prevalence rates of axis I disorders. Overall, 93\% of the patients were diagnosed with at least one axis I diagnosis, most frequently somatoform disorders (83.7\%). Besides the criticism of the specificity of somatoform disorders $[2,3,29]$, a syndrome overlap of depression, anxiety and somatization may account for the high comorbidity on axis I $[6,7]$. A high rate of comorbid PDs $(62.8 \%)$ was also confirmed. Unlike previous findings of a predominance

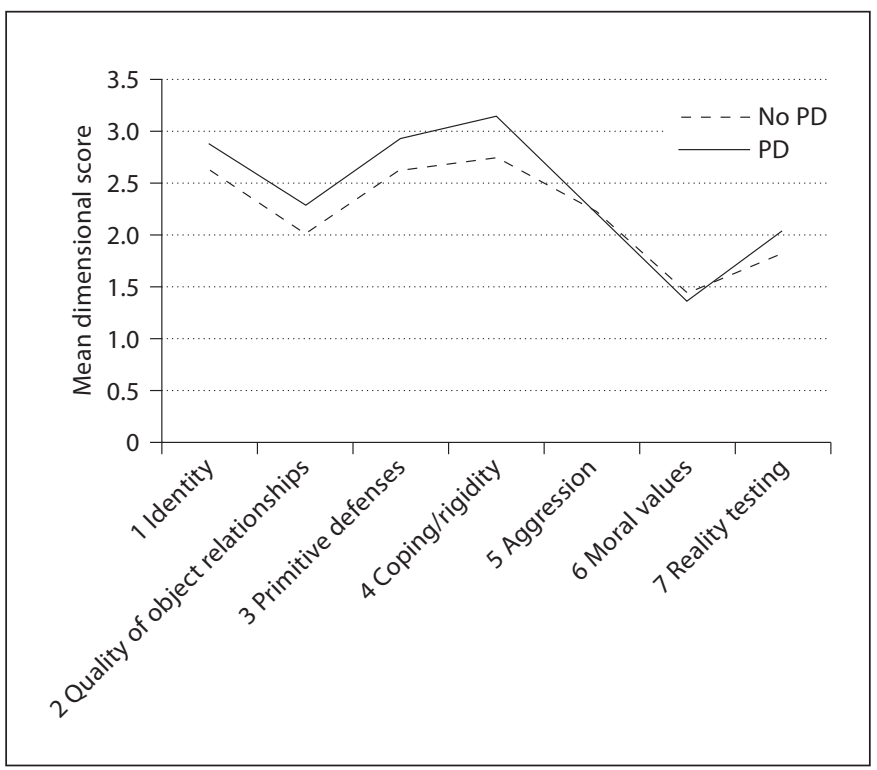

Fig. 1. Group comparison: profile of STIPO dimensional ratings of subjects with PD $(n=27)$ versus those without PD $(n=16)$.

of histrionic, dependent and paranoid PDs [10-12], in our sample, obsessive-compulsive PD was most frequent. An investigation of CPPs in different institutional settings has shown psychiatric pain clinic patients to be more obsessive in comparison to primary care patients [30].

From the total sample, $58.2 \%$ of the patients were classified as having borderline PO, predominantly borderline I (46.5\%), which corresponds to moderate structural impairment. In comparison to an estimation of $10 \%$ prevalence in the general population [31], the prevalence of borderline PO in our sample was substantially high. The prevalence rate for DSM-IV BPD of $25.6 \%$ was also substantially higher than the rate of $1-2 \%$ in the general population [32].

According to the STIPO dimensional ratings, the most severe impairment was found in the STIPO dimension 'coping/rigidity', followed by 'primitive defenses' and 'identity'. Coping is one of the most discussed psychological variables in CPP literature [33]. Furthermore, chronic pain is frequently related to an inherent self-regulation difficulty around the experience of pain [34]. This self-regulation difficulty might be associated with the use of primitive defensive operations. Moreover, passive coping and primitive defense mechanisms have negative reinforcing effects on the individual's capacity to invest in work or studies and leisure activities, which are key elements of 'identity'. 
The number of axis I disorders corresponded to the STIPO level of PO, and a moderate association was found between the number of axis II disorders and the STIPO level of PO. However, the STIPO dimensional ratings of patients with $\mathrm{PD}$ and patients without PD showed no significant differences. Thus, the dimensional ratings revealed a homogeneous profile of impairment in all of the 7 dimensions of the STIPO independent of comorbid PD. Structural impairment of the personality cannot be explained as a result of comorbid PD, but rather could be regarded as an independent dimension in chronic pain. As a consequence, the diagnosis and treatment of structural deficits represents a crucial extension of clinical axis I and II diagnoses. Larger samples and longitudinal studies using the STIPO may clarify the bidirectional relationship between pain and personality, such that pain intensifies personality pathology and personality pathology intensifies the experience and perception of pain.

Several limitations of the study have to be noted. The first limitation is the comparably small sample size. Further limitations are the participants' characteristics, including a predominance of women, heterogeneous pain symptoms and the preselection of the sample (referral to a psychiatric unit). Moreover, the STIPO is a relatively new instrument, and comparison values for CPPs are not yet available.

One strength of the present study is the assignment of an instrument to the investigation of CPPs that contributes to the general discussion on a revision of the DSM-IV and to the specific demands of the assessment of CPPs. There is a growing body of research on axis I and axis II comorbidity associating personality dysfunction with more challenging courses of axis I symptomatology [35, 36]. The recent literature has focused on the problematic boundary between axis I and axis II [37] and has emphasized the need to work towards a more unified model of personality, PDs and clinical disorders [38]. The DSM-V Research Planning Conference on PDs has suggested developing a more fundamental revision through an in- tegration of alternative dimensional models of PD and general personality structure $[39,40]$. Beyond that, psychotherapists' needs for diagnoses and classification are different from those of the medical model of psychiatric disorders as used in the DSM manuals [41].

With regard to CPPs, the recent literature has addressed the complexity of chronic pain conditions and the difficulties involved in the assessment of personality and personality pathology [42]. The literature suggests the need for multidimensional qualitative tools to assess qualitative aspects of chronic pain and its impact on emotional and social functions [43].

\section{Conclusion}

The STIPO contributes to the proposal for a dimensional classification of PDs as well as to proposals for a more unified model of personality, PDs and clinical disorders. Addressing the question of severity in the classification of PD, the STIPO represents a structured and operationalized approach towards a refined assessment by differentiating 6 levels of PO. In addition, the dimensional ratings focus on the most salient dysfunctions at a given time.

The investigation of CPPs according to the model of PO may enhance knowledge of personality features associated with the development and maintenance of chronic pain conditions. From a psychodynamic point of view, the investigation of structural aspects of personality is central for diagnostics, treatment planning and evaluation of the treatment response, in addition to descriptive diagnostic approaches.

\section{Acknowledgements}

The authors thank Andrea Naderer, MD, and Nikolaus Thierry, MD, for data collection.

\section{References}

Personality Organization and Psychiatric Classification in Chronic Pain Patients
1 Merskey H, Bogduk N: Classification of Chronic Pain: Description of Chronic Pain Syndromes and Definitions of Pain Terms, ed 2. Seattle, IASP Press, 1994.

2 Aigner M, Bach M: Clinical utility of DSMIV pain disorder. Compr Psychiatry 1999;40: 353-357.

3 Mayou R, Kirmayer LJ, Simon G, Kroenke K, Sharpe M: Somatoform disorders: time for a new approach in DSM-V. Am J Psychiatry 2005;162:847-855.
4 Dimsdale JE, Creed FH: The proposed diagnosis of somatic symptom disorders in DSM$\mathrm{V}$ to replace somatoform disorders in DSMIV - a preliminary report. J Psychsom Res 2010;68:99-100.

5 Dersh J, Polatin PB, Gatchel RJ: Chronic pain and psychopathology: research findings and theoretical considerations. Psychosom Med 2002;64:773-786. 
6 Loewe B, Spitzer RL, Williams JBW, Mussell M, Schellberg D, Kroenke K: Depression, anxiety and somatization in primary care: syndrome overlap. Gen Hosp Psychiatry 2008;30:191-199.

7 Katon W, Lin EHB, Kroenke K: The association of depression and anxiety with medical symptom burden in patients with chronic medical illness. Gen Hosp Psychiatry 2007; 29:147-155.

8 Weisberg J, Gallagher R, Gorin A: Personality disorders in chronic pain: a longitudinal approach to validation of diagnosis. Proceedings of the Annual Meeting of the American Pain Society, Washington, 1996.

9 Burton K, Polatin PB, Gatchel RJ: Psychosocial factors and the rehabilitation of patients with chronic work-related upper extremity disorders. J Occup Rehabil 1997;7:139-153.

10 Reich J, Rosenblatt R, Tupin J: DSM-III: a new nomenclature for classifying patients with chronic pain. Pain 1983;16:201-206.

11 Fishbain DA, Goldberg M, Meagher BR, Steele R, Rosomoff $\mathrm{H}$ : Male and female chronic pain patients categorized by DSMIII psychiatric diagnostic criteria. Pain 1986; 26:181-197.

12 Polatin PB, Kinney RK, Gatchel RJ, Lillo E, Mayer TG: Psychiatric illness and chronic low-back pain. The mind and the spine which goes first? Spine 1993;18:66-71.

13 Monsen K, Havik OE: Psychological functioning and bodily conditions in patients with pain disorder associated with psychological factors. Br J Med Psychol 2001;74: 183-195.

14 Nitch SR, Boone KB: Normal personality correlates of chronic pain subgroups. J Clin Psychol Med Settings 2004;11:203-209.

15 Conrad R, Schilling G, Bausch C, Nadstawek J, Wartenberg HC, Wegener I, Geiser F, Liedtke R: Temperament and character personality profiles and personality disorders in chronic pain patients. Pain 2007;133:197209.

16 Vendrig AA: The Minnesota Multiphasic Personality Inventory and chronic pain: a conceptual analysis of a long-standing but complicated relationship. Clin Psychol Rev 2000;20:533-559.

17 Wallerstein RS: Assessment of structural change in psychoanalytic therapy and research; in Shapiro T (ed): The Concept of Structure in Psychoanalysis. Madison, International University Press, 1991, pp 241-261.

18 Kernberg OF: A psychoanalytic theory of personality disorders; in Clarkin JF, Lenzenweger MF (eds): Major Theories of Personality Disorder. New York, Guilford Press, 1996, pp 106-140.
19 Rudolf G, Grande T, Henningsen P: Die Struktur der Persönlichkeit. Vom theoretischen Verständnis zur psychotherapeutischen Anwendung des psychodynamischen Strukturkonzepts. Stuttgart, Schattauer, 2002.

20 Clarkin JF, Caligor E, Stern B, Kernberg OF: Structured Interview of Personality Organization (STIPO). New York, Weill Medical College of Cornell University, 2003.

21 Hörz S, Rentrop M, Fischer-Kern M, Schuster P, Kapusta ND, Buchheim P, Doering S: Personality structure and clinical severity of borderline personality disorder. Z Psychosom Med Psychother 2010;56:136-149.

22 Fischer-Kern M, Buchheim A, Hörz S, Schuster P, Doering S, Kapusta ND, Taubner S, Tmej A, Rentrop M, Buchheim P, Fonagy P: The relation of personality organization, reflective functioning, and psychiatric classification in borderline personality disorder. Psychoanal Psychol, in press.

23 Doering S, Hörz S, Rentrop M, Fischer-Kern M, Schuster P, Benecke C, Buchheim A, Martius P, Buchheim P: Transference-focused psychotherapy v. treatment by community psychotherapists for borderline personality disorder: randomized controlled trial. $\mathrm{Br}$ Psychiatry 2010;196:389-395.

24 Walter M, Berth H, Selinger J, Gerhard U, Küchenhoff J, Frommer J, Dammann G: The lack of negative affects as an indicator for identity disturbance in borderline personality disorder: a preliminary report. Psychopathology 2009;42:399-404.

25 Wittchen HU, Zaudig M, Fydrich T: SKID-I Strukturiertes Klinisches Interview für DSM-IV, Achse I. Göttingen, Hogrefe, 1997.

26 Fydrich T, Renneberg B, Schmitz B, Wittchen HU: Strukturiertes Klinisches Interview für DSM-IV Achse II: Persönlichkeitsstörungen. Göttingen, Hogrefe, 1997.

27 Stern BL, Caligor E, Clarkin JF, Critchfield KL, Hörz S, Maccornack V, Lenzenweger MF, Kernberg OF: Structured Interview of Personality Organization (STIPO): preliminary psychometrics in a clinical sample. J Pers Assess 2010;92:35-44.

28 Hörz S: A Prototype of Borderline Personality Organization Assessed by the Structured Interview of Personality Organization (STIPO). Hamburg, Kovac, 2007.

29 Creed F, Barsky A: A systematic review of the epidemiology of somatisation disorder and hypochondriasis. J Psychosom Res 2006;56: 391-408.
30 Merskey H, Lau CL, Russell ES, Brooke RI, James M, Lappano S, Neilsen J, Tilsworth RH: Screening for psychiatric morbidity. The pattern of psychological illness and premorbid characteristics in four chronic pain populations. Pain 1987;30:141-157.

31 Kernberg OF: A psychoanalytic theory of personality disorders; in Clarkin JF, Lenzenweger MF (eds): Major Theories of Personality Disorder. New York, Guilford Press, 1996, pp 106-140.

32 Lieb K, Zanarini MC, Schmahl C, Linehan MM, Bohus M: Borderline personality disorder. Lancet 2004;364:453-461.

33 Van Damme S, Crombez G, Eccleston C: Coping with pain: a motivational perspective. Pain 2008;139:1-4.

34 Sansone RA, Whitecar P, Meier BP, Murry A: The prevalence of borderline personality among primary care patients with chronic pain. Gen Hosp Psychiatry 2001;23:193-197.

35 Sheets E, Craighead WE: Toward an empirically based classification of personality pathology. Clin Psychol Sci Pract 2007;14:7793.

36 Huang Y, Kotov R, De Girolamo G, Preti A, Angermeyer M, Benjet C, Demyttenaere K, Kessler RC: DSM-IV personality disorders in the WHO World Mental Health Surveys. Br J Psychiatry 2009;195:46-53.

37 Widiger TA: Personality disorder and Axis I psychopathology: the problematic boundary of Axis I and Axis II. J Pers Disord 2003;17: 90-108.

38 Krueger RF: Continuity of Axes I and II: toward a unified model of personality, personality disorders, and clinical disorders. J Pers Disord 2005;19:233-261.

39 Widiger TA, Simonsen E, Krueger R, Livesley WJ, Verheul R: Personality disorder research agenda for the DSM-V. J Pers Disord 2005;19:315-338

40 Widiger TA: A dimensional model of psychopathology. Psychopathology 2005;38: 211-214.

41 Mundt C, Backenstrass M: Psychotherapy and classification: psychological, psychodynamic, and cognitive aspects. Psychopathology 2005;38:219-222.

42 Main CJ, Richards HL, Fortune DG: Why put new wine in old bottles: the need for a biopsychosocial approach to the assessment, treatment, and understanding of unexplained and explained symptoms in medicine. J Psychosom Res 2000;48:511-514.

43 Breivik H, Borchgrevink PC, Allen SM, Rosseland LA, Romundstad L, Breivik Hals EK, Kvarstein G, Stubhaug A: Assessment of pain. Br J Anaesth 2008;101:17-24. 